\title{
Hierarchical Generalized Linear Mixed Models for Multilevel Analysis of Indonesian Student's PISA Mathematics Literacy Achievement
}

\author{
Tonah $^{1 *}$, Anang Kurnia ${ }^{2}$, Kusman Sadik². \\ \{tonah31780406@gmail.com ${ }^{1}$, anangk@apps.ipb.ac.id ${ }^{2}$, kusmansadik@gmail.com ${ }^{2}$ \} \\ ${ }^{1}$ Mathematics Education Department, Universitas Swadaya Gunung Jati, Cirebon, 45132, Indonesia \\ ${ }^{2}$ Statistics Department, IPB University, Bogor, 16680, Indonesia
}

\begin{abstract}
Generally, learning assessment and evaluation data in educational has a hierarchical structures one of which is PISA data. Multilevel models are methods that can be used to analyse hierarchical data structures and can be considered as HGLM models. This study has two objectives namely, examine the distribution of variable mathematical literacy and selecting the best HGLM model to determine student and school level variables that significantly influence students' mathematical literacy achievement. The result we have obtained are mathematical literacy achievement has lognormal distribution and M7 model is the best model.
\end{abstract}

Keywords: Hierarchical generalized linear mixed models, multilevel generalized linear models, PISA mathematics literacy achievement.

\section{Introduction}

Research in the field of education often traces the relationship between individuals who study with the environment in which they exist. The quality of individual learning outcomes is influenced by the environment or group he is in, such as in the place of study and residence. This environment is also determined by individuals forming groups. Most of this education data have a hierarchical structure. As an illustration, based on where he studied, students are nested in nested classes and classes in schools. In this case, there are three levels; the lowest level is students/individuals, classes at level 2 and schools at level three. Data with such structures is known as multilevel data. Hox et al. (2018) suggest that multilevel research is related to population and hierarchical structure. The samples are considered as multistage samples. In general, the observations of individuals in multistage samples are not independent. Such data conditions cannot be analysed by a standard statistical model that has strict assumptions in the independence of individual observations. Violations of these assumptions raise problems with model parameter inference in classical statistical analysis.

Goldstein introduces multilevel models to overcome problems that arise in survey data as well as in hierarchically structured data. The historical roots of the development of analysis and interpretation for multilevel models emerged in research in education and Sociology (Hox and Roberts, 2011). Ubaidillah et al. convey the advantages of the multilevel model for hierarchical data that refers to the opinions of Goldstein and Hox. First, information from several levels can be analysed simultaneously in one statistical analysis; second, 
multilevel models can calculate the effect of variants of each level on response variants so that this model provides more information than classical statistical analysis (classical regression) which only analyses one level using aggregation and disaggregation techniques.

Multilevel data analysis on education focuses on the principles and procedures used in evaluating educational progress. Schools, as a higher level, affect the achievement of student learning outcomes. The Program for International Student Assessment (PISA) is an international learning achievement assessment system that focuses on measuring the ability of 15 -year-olds in the field of reading literacy, mathematical literacy and literacy in the field of science. PISA produces multilevel data in education with students at the lowest level. The Economic Co-operation and Development (OECD) Organization organise PISA. This program was first conducted in 2000 and subsequently periodically every three years. Participants in the PISA program are OECD member countries and some countries that are not OECD members (including Indonesia). Each implementation always includes measuring three literacy abilities, but there is one literacy that is determined to be the main focus, and it has been scheduled periodically. The main focus measured in PISA 2012 is reading literacy. In 2015 focused on scientific literacy and the implementation of what has just passed in 2018, focusing on mathematical literacy. PISA data can be analysed and used as a reference for policymakers to evaluate and improve education in various aspects.

This study has two objectives in analysing the mathematical literacy skills of Indonesian students in PISA 2015 using hierarchical generalised linear mixed models (HGLM). First, examine the distribution of variable mathematical literacy as a basis for determining the distribution will be used in the HGLM model. Second, applying and selecting the best HGLM model to determine student and school level variables that significantly influence students' mathematical literacy skills in PISA 2015.

\section{Materials}

Many researchers analyse PISA data with a variety of methods, including $\mathrm{Wu} \mathrm{H}$. et al. (2019) uses multilevel modelling with two objectives. First, explore the relationship between principals' leadership based on self-assessment and student achievement with control of student and school background variables. Second, to analyse the effect of interactions between principals' leadership and school context variables on student achievement; Özdemir (2016) also investigated the achievement of student mathematics literacy in Turkey in PISA in 2012 with multilevel modelling. Gursakal et al. (2016) use quantile regression to trace the relationship between students' mathematics achievement in Turkey in PISA 2012 with the characteristics of students, family socio-economic background, familiarity with information and communication technology and climate in schools. Skrondal and Heryeth (2009) use a generalised multilevel linear model with an empirical Bayesian approach that is used to investigate the contextual influence of socio-economic variables on literacy. In Indonesia, several studies apply multilevel models in the field of education, among others, carried out by Tantular (2009) which analyses the scores of the test subjects in the statistical method using linear multilevel models. Widiastuti, M. (2011) applied random intercept multilevel regression on Indonesian mathematics achievement in TIMSS 2007. Zulvia (2017) analysed the UN scores of high school students in West Java in 2011 to 2014 which combined analysis of multilevel linear models with panel data analysis using linear mixed models.

Goldstein (2011) states the two-level modelling as follows:

The level 1 model in each group is expressed by 


$$
y_{i j}=\beta_{0 j}+\sum_{q=1}^{p} \beta_{q j} X_{q i j}+e_{i j}
$$

With $p$ state the number of variables at level $1, i$ is an index for individuals, $i=1,2, \ldots, n_{j}$, where $j$ is a group, $j=1,2, \ldots, m$.

The matrix form for Equation 1 as follows:

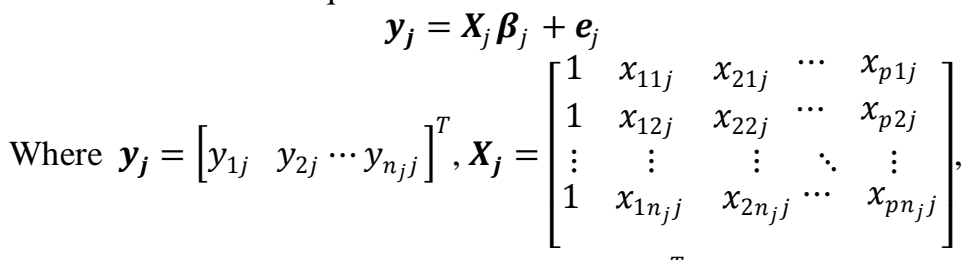

$\boldsymbol{\beta}_{\boldsymbol{j}}=\left[\begin{array}{lll}\beta_{1 j} & \beta_{2 j} \cdots & \beta_{p j}\end{array}\right]^{T}, \boldsymbol{e}_{\boldsymbol{j}}=\left[\begin{array}{llll}e_{1 j} & e_{2 j} \cdots e_{n_{j} j}\end{array}\right]^{T}$.

The researcher formed Model 2 by making the coefficient on the level 1 model as a response explained by explanatory variables at level 2 . Thus the regression coefficient in model 1 is possible to have different values between one group and another group.

$$
\beta_{q j}=\gamma_{0 q}+\sum_{r=1}^{l} \gamma_{r q} Z_{r j}+u_{q j}
$$

The matrix form from Equation 3 as follows:

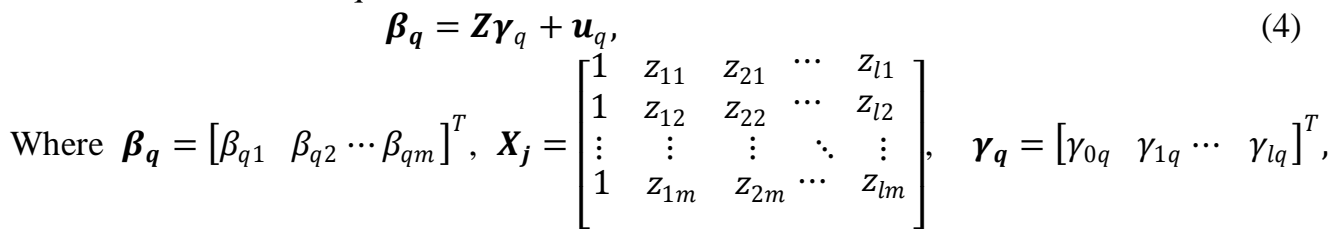
$\boldsymbol{u}_{\boldsymbol{q}}=\left[\begin{array}{llll}u_{q 1} & u_{q 2} & \cdots & u_{q m}\end{array}\right]^{T}$.

Hierarchical modelling with two levels has several underlying assumptions (Hox, 1995; and Kreft, 2006; Ubaidillah et al., 2017). Level 1 has several assumptions, that is, between residuals are mutually independent $\left(\operatorname{Cov}\left(e_{i j}, e_{i^{*} j}\right)=0 ; i \neq i^{*}, i, i^{*}=1,2, \cdots, n_{j}\right), e_{i j}$ have a normal distribution, $E\left(\boldsymbol{e}_{k}\right)=\mathbf{0}$ and $\operatorname{Var}\left(\boldsymbol{e}_{k}\right)=\sigma_{[e] j}^{2} \boldsymbol{I}_{n_{j}}$, dengan $[e] j$ is the residual variance of level 1 model jth group. Assumptions at level 2 are mutually independent residuals $\left(\operatorname{Cov}\left(u_{q j}, u_{q^{*} j}\right)=0 ; q \neq q^{*}, q, q^{*}=1,2, \cdots, m\right), u_{q j}$ have a normal distribution, $E\left(\boldsymbol{u}_{q}\right)=\mathbf{0}$ dan $\operatorname{Var}\left(\boldsymbol{u}_{q}\right)=\boldsymbol{T}_{q}$, where

$\boldsymbol{T}_{\boldsymbol{q}}=\left[\begin{array}{cccc}\sigma_{[u] q 11}^{2} & \sigma_{[u] q 21}^{2} & \cdots & \sigma_{[u] q m 1}^{2} \\ \sigma_{[u] q 12}^{2} & \sigma_{[u] q 22}^{2} & \cdots & \sigma_{[u] q m 2}^{2} \\ \vdots & \vdots & \ddots & \vdots \\ \sigma_{[u] q 1 m}^{2} & \sigma_{[u] q 2 m}^{2} & \cdots & \sigma_{[u] q m m}^{2}\end{array}\right]$, where $[e] j$ is the level 2 residual model variance for the regression coefficient $q$-th in $j$-th group. While between levels, the residual assumptions at level 1 and level 2 are mutually independent $\left(\operatorname{Cov}\left(e_{i j}, u_{q j}\right)=0\right)$.

The combined model formed by substituting Equation 3 to Equation 1 and the matrix form written as

$$
\boldsymbol{y}_{j}=\boldsymbol{X}_{j} \boldsymbol{Z}_{j} \boldsymbol{\gamma}+\boldsymbol{X}_{j} \boldsymbol{u}_{j}+\boldsymbol{e}_{j}
$$

Where $\boldsymbol{X}_{j} \boldsymbol{Z}_{j} \boldsymbol{\gamma}$ is fixed effect and $\boldsymbol{X}_{j} \boldsymbol{u}_{j}+\boldsymbol{e}_{j}$ is a random effect, $E\left(\boldsymbol{y}_{j}\right)=\boldsymbol{X}_{j} \boldsymbol{Z}_{j} \boldsymbol{\gamma}$ and $\operatorname{Var}\left(\boldsymbol{y}_{j}\right)=\boldsymbol{X}_{j} \boldsymbol{T} \boldsymbol{X}_{\boldsymbol{j}}^{\boldsymbol{T}}+\boldsymbol{\sigma}_{\boldsymbol{j}}^{2} \boldsymbol{I}_{\boldsymbol{n} \boldsymbol{j}}$. A linear multilevel model is one form of a linear mixed model that accommodates the interaction between variables at different levels.

In general, achievement scores in learning are always not negative and hierarchical. For modeling with more results, it is better to test the distribution of the response variable, if 
the test obtained abnormal distribution but still in the exponential family (e.g. gamma distribution, normal log, Weibull, binomial, Poisson and so on) then the multilevel model is linear in Equation 5 not appropriate to use. Before conducting a distribution test statistically; the first step is to select the distribution candidate. Selection of candidate distribution can be done based on information about the interval value of the response variable in a population. However, if this information not obtained, then the selection of distribution candidates can use several graphs including histograms, cumulative density function (CDF) from empirical distribution, skewness-kurtosis charts proposed by Cullen and Frey (Delignete, 2018). Related to the ability of PISA mathematical literacy, it has values that are not negative. The opportunity distribution that has these characteristics include gamma, Weibull and lognormal distributions. These three distributions used as candidates for testing data on mathematical literacy skills.

Furthermore, distribution testing can be done. There are three classical methods for testing data distribution, namely Cramer Von Mises test, Kolmogorov-Smirnov test and Anderson Darling test. Distribution testing in this study uses the Anderson Darling test which is more flexible compared to the Kolmogorov-Smirnov test.

If based on the test results obtained abnormal distribution but still part of the exponential family, the data can be analysed using multilevel generalised linear models, which are an extension of the linear multilevel model. The formulation of multilevel generalised linear models based on generalised linear models. Generalised linear models (GLM) are the development of linear models. GLM includes three components, namely a random component, a systematic component and a connection function. According to McCullagh and Nelder (1989), the random component is a response variable with distribution which includes an exponential family with $E(y)=\mu$; Systematic components include covariates $x_{1}, x_{2}, \cdots, x_{p}$ which composes a linear predictor $\eta$ which is defined by $\eta=\sum_{j=1}^{p} x_{j} \beta_{j}$. While the connecting function $g(\mu)=\eta, g($.$) is a differentiated monotonic function.$

Referring to GLM, multilevel generalised linear models which are GLM for data with the hierarchical structure expressed as $(\mu)=g\left(\boldsymbol{X}_{j} \boldsymbol{Z}_{j} \boldsymbol{\gamma}+\boldsymbol{X}_{j} \boldsymbol{u}_{j}\right), g($.$) depends on the$ distribution of $y$, if $y$ have a normal distribution then $g(\mu)=\mu$.

The multilevel generalised linear model is part of GLMM and is certainly also included in HGLM. HGLM first introduced by Lee and Nelder (1996). HGLM is defined as follows: Suppose $\mathrm{y}$ is a response variable, and $\mathrm{u}$ is an unobserved random component.

a. Log likelihood conditional from $y$ if $u$ given is a GLM in the form: $l\left(\theta^{\prime}, \phi, y \mid u\right)=$ $\frac{\left\{y \theta^{\prime}-b\left(\theta^{\prime}\right)\right\}}{a(\phi)}+c(y, \phi)$,

where $\theta^{\prime}$ and $\phi$ sequentially are canonical parameters and dispersion parameters, $\mu^{\prime}=$ $E(Y \mid u), \eta^{\prime}=g\left(\mu^{\prime}\right), g\left(\mu^{\prime}\right)$ is a connecting function for GLM which describes the conditional distribution of $y$ if $u$ given. Linear predictors $\eta^{\prime}=\eta+v$, where $\eta=\boldsymbol{X} \boldsymbol{\beta}$ for GLM and $v=g(u)$ for some powerful monotonous functions from $u$.

b. Distribution from $u$ assumed to be at the beginning following the conjugate distribution of GLM. Modeling $\eta^{\prime}$ includes a model of the influence of fixed and dispersion models for $v$ which can explain overdispersion (if it exists). The linear mixed model is HGLM called normal HGLM. The first normal is referred to conditional distribution from $y$ if $u$ given, and the second is distribution of $u(=v)$.

$\mathrm{H}$-likelihood based on the likelihood function is useful to the estimation of HGLM parameters. H-likelihood combines the fixed component likelihood and random component 
likelihood in one function. This merger was done by summing the log-likelihood of the fixed component with the log-likelihood of the random component. h-likelihood defined as:

$$
h=l\left(\theta^{\prime}, \phi ; y \mid u\right)+l(a ; v)
$$

$l(a ; v)$ and $l\left(\theta^{\prime}, \phi ; y \mid u\right)$ each is a logarithm of the density function of $v$ with the parameter $a$ and logarithm from the density function $y \mid u . v$ is a canonical scale of random influence $u$ which is invariant to the transformation and parameterisation of random parameters (Lee et al. 2017). Therefore, to make it easier, $l\left(\theta^{\prime}, \phi ; y \mid u\right)$ can be obtained from the density function of $y \mid v$. Thus it can be said that h-likelihood is the logarithm of the function of the combined density of $y$ and $v$. The h-likelihood estimator for HGLM obtained by maximising $h$ to $\theta$ and $v$ simultaneously, that is by determining the solution of the system of equations $\frac{d h}{d \theta}=0$ and $\frac{d h}{d v}=0$. In the context of multilevel generalised linear multilevel, determine the solution of the system of equations $\frac{d h}{d \beta}=0$ and $\frac{d h}{d v}=0$. h-likelihood can eliminate the problem in estimating REML, which is often difficult to obtain the integral (of the combined likelihood of random influences) needed to get a fixed effect marginal likelihood function.

\section{Methods}

\section{Data Source}

This study uses 2015 PISA data for Indonesia, which has been published by the OECD. The data used in this study is the screening data, which includes data on the results of the PISA test (mathematics literacy achievement) of students and questionnaire data provided to students and principals. In Indonesia, the 2015 PISA participants were 4925 students and 182 schools. Details of variables used at the student level and the school level are as follows:

1. The variables at level 1 (students) consist of mathematical literacy abilities, which are the average of the plausible value of math as the response variable (LM). The explanatory variables are students 'socio-economic background variables (ESCS), variables that reflect students' confidence in their ability to overcome difficulties and solve tasks effectively (SCIEFF) related to the field of science, instrumental motivation (INSTSCIE), epistemological belief (EPIST)

2. Level two variables (school) consist of principals' general leadership based on selfassessment (LEAD), lack of educational material (EDUSHORT), number of science teachers (TOTST), proportion of certified teachers (PROSTCE), ratio of students and teachers (STRATIO), school ownership status (SCHTYPE), the school's socio-economic background variable which is the average of all economic background variables of students in one school (ESCS_SCH).

In general, the analysis carried out in this study consisted of four stages. First, explore the data and analyse to get initial information on the value of the correlation between variables at the student level and the correlation between variables at the school level to see the existence of inter-variable multicollinearity. Second, determine candidate distribution using the information on the possible range of values for population literacy abilities supported from the histogram, CDF, p-p plot, empirical q-q plot, and skewness and kurtosis charts. Furthermore, testing the opportunity distribution for the response variable, namely mathematical literacy ability with the Anderson-Darling test. Third, do modelling gradually 
with HGLM using the distribution of test results, then compare and select the best model based on the value of cCIC, RMSE, likelihood ratio test (LR Test) and residual plot characteristics of the models analysed. The models that compared are

1. $M_{0}$ : Random intercept model is a model that does not contain variables both at the student level and at the school level (only includes intercepts for both fixed and random components). This model can be used to see the random influence of schools.

2. $M_{1}$ : The fixed components of the model only contain variables at the student level, namely ESCS, SCIEFF, INSTSCIE and EPIST and on random components contain intercepts.

3. $M_{2}$ : The fixed components and random components in the model only contain variables at the student level namely ESCS, INSTSCIE and EPIST.

4. $M_{3}$ : The fixed components of the model contain student-level variables (ESCS, INSTSCIE and EPIST) and school-level variables (LEAD, EDUSHORT, PROSTCE, TOTST, STRATIO, ESCS_SCH, SCHTYPE) without variable interactions at the student level with variables at the school level and components random only load intercept.

5. $M_{4}$ : The fixed components of the model contain student-level variables (ESCS, INSTSCIE and EPIST) and school-level variables (LEAD, EDUSHORT, PROSTCE, TOTST, STRATIO, ESCS_SCH, SCHTYPE) without variable interactions at the student level with variables at the school level and components randomly contains student-level variables.

6. $M_{5}$ : The fixed components in the model contain student-level variables (ESCS, INSTSCIE and EPIST) and school-level variables (LEAD, EDUSHORT, PROSTCE, TOTST, STRATIO, ESCS_SCH, SCHTYPE) along with variable interactions at the student level with school-level variables and components random only contains intercepts.

7. $M_{6}$ : The fixed components in the model contain student-level variables (ESCS, INSTSCIE and EPIST) and school-level variables (LEAD, EDUSHORT, PROSTCE, TOTST, STRATIO, ESCS_SCH, SCHTYPE) along with variable interactions at the student level with school-level variables and components randomly load variables at the student level.

The last stage, interpret the best-chosen model.

\section{Result and Discussion}

The average achievement of mathematical literacy between private schools and public schools is quite different but has a relatively similar level of diversity. Private schools reach a higher average than public schools. Students with mathematics literacy achievements come from public schools while the lowest scores obtained by private school students. Description statistics are given in Table 1.

Table 1 . Statistics description of achievement of mathematical literacy

\begin{tabular}{llr}
\hline SCHTYPE & & \multicolumn{1}{c}{ Statistic } \\
\hline Private & Mean & 418.29385 \\
& Median & 410.81880 \\
& Std. Deviation & 73.17019 \\
& Minimum & 214.31160 \\
& Maximum & 635.98480 \\
Public & Mean & 396.51691
\end{tabular}


The initial two analyses of the PISA data aim to detect the presence of multicollinearity between explanatory variables. First, calculate the Pearson correlation to see a linear relationship between students' mathematical literacy achievements and the explanatory variables (characteristics) of students and explanatory variables at the school level. Second, determine the VIP value between the response variable and the explanatory variable. The correlation and VIP values of the explanatory variables are in Table 2 to Table 5.

Table 2. Correlation between achievement of mathematical literacy and student characteristic variables

\begin{tabular}{lcccc}
\hline & LM & INSTSCIE & SCIEEFF & EPIST \\
\hline INSTSCIE & $.042^{* *}$ & & & \\
SCIEEFF & $.092^{* *}$ & $.124^{* *}$ & & \\
EPIST & $.203^{* *}$ & $.145^{* *}$ & $.074^{* *}$ & \\
ESCS & $.478^{* *}$ & .023 & $.162^{* *}$ & $.137^{* *}$ \\
\hline \multicolumn{4}{c}{ Correlation is significant at the 0.01 level (2-tailed) } \\
\end{tabular}

Table 3. VIP value of student characteristics

\begin{tabular}{lc}
\hline Variable & VIF \\
\hline SCIEEFF & 1.044 \\
EPIST & 1.042 \\
ESCS & 1.044 \\
INSTSCIE & 1.035 \\
\hline
\end{tabular}

Table 4. Correlation between achievement of mathematical literacy and school characteristics variables

\begin{tabular}{lccccr}
\hline & LM & EDUSHORT & TOTST & STRATIO & ESCS_SCH \\
\hline EDUSHORT & $-.250^{* * *}$ & & & & \\
TOTST & $.420^{* *}$ & $-.237^{* *}$ & & & \\
STRATIO & $.117^{* *}$ & $-.035^{*}$ & $.156^{* *}$ & & \\
ESCS_SCH & $-.059^{* * *}$ & .028 & $.211^{* *}$ & .002 & \\
PROATCE & $.217^{* *}$ & $-.143^{* *}$ & $.364^{* *}$ & $.070^{* *}$ & $.052^{* *}$ \\
\hline
\end{tabular}

".* Correlation is significant at the 0.01 level (2-tailed)

Table 5. VIP values for school characteristics

\begin{tabular}{ll}
\hline Variabel \\
\hline
\end{tabular}




\begin{tabular}{ll} 
LEAD & 1.086 \\
EDUSHORT & 1.071 \\
PROSTCE & 1.185 \\
TOTST & 1.381 \\
STRATIO & 1.030 \\
ESCS_SCH & 1.056 \\
\hline
\end{tabular}

Based on the correlation values, most of which are very small. The highest correlation value is 0.36 , which is the correlation between the proportion of certified teachers and the number of science teachers in schools. VIP values that are less than 2 indicate that the data in this study do not occur multicollinearity between variables explanation so that it does not require additional treatments to do HGLM modelling.

Fitting of distribution directing to gamma distribution and lognormal distribution. Empirically for mathematical literacy skills, based on the characteristics of its value range and graphic methods with a q-q plot, p-p plot and graphs of skewness and kurtosis. It is shown in Figure 1 and Figure 2, namely that the gamma distribution and lognormal distribution can better explain the distribution centre (p-p plot) and "tail" of the distribution (q-q plot). However, it still needs to be tested statistically on the best distribution of opportunities for mathematical literacy skills.
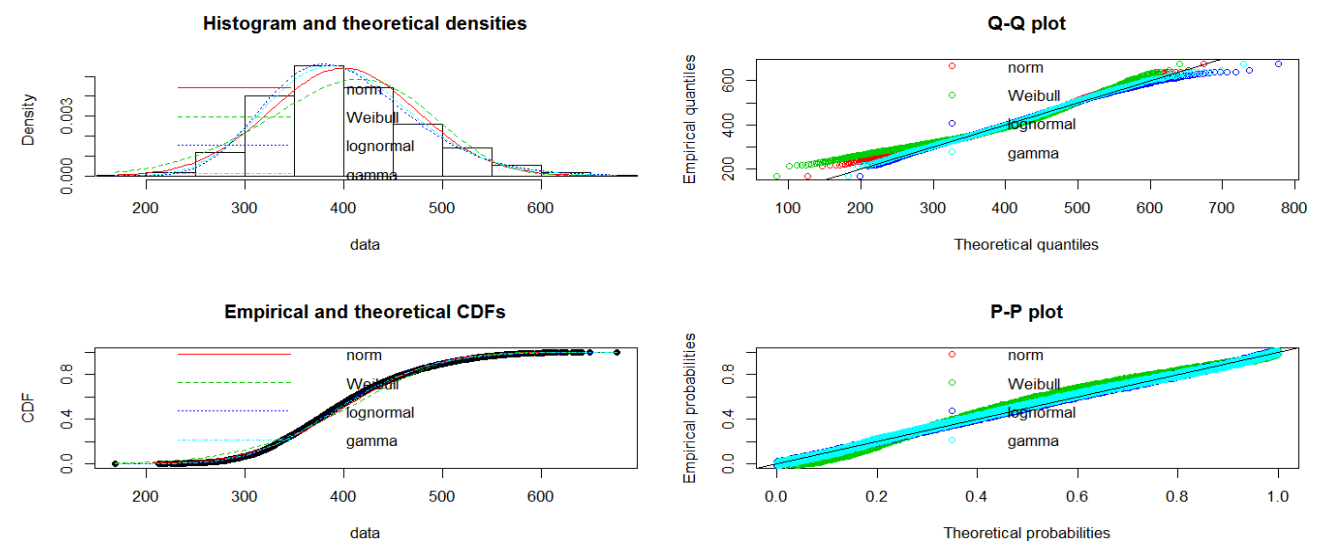

Fig. 1. Godness-of-fit 


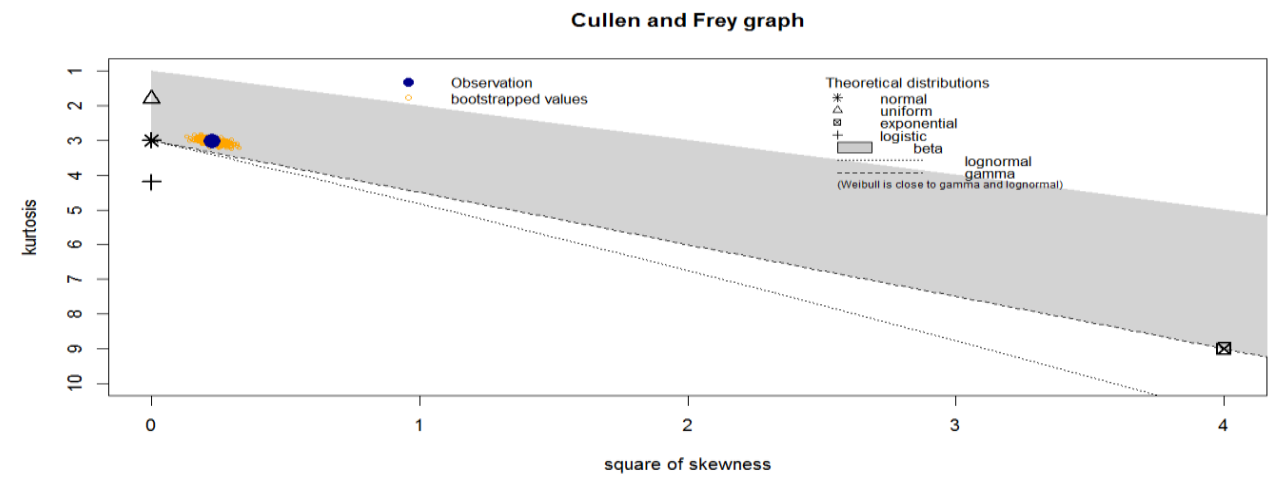

Fig. 2. Skewness-Kurtosis

The results of testing the opportunity distribution with the Anderson-Darling test obtained the value of the goodness of fit statistic of the gamma distribution of 5.056 and for the lognormal distribution of 1.476. The goodness of fit is a value that describes the distance between parametric distributions that are fitting and empirical distribution, the smaller, the better. The smallest AIC and BIC values can be used to choose the best distribution of opportunities. The AIC values of the gamma and lognormal distributions are 56147.01 and 56127. 04 respectively, while the BIC value of gamma distribution is 56160.02 and the normal log distributed to 56140.05. Based on the Goodness of fit, AIC and BIC, it can be concluded that mathematical literacy ability is lognormal distribution. Thus, HGLM modelling in PISA data uses a lognormal distribution with an identity connecting function.

Table 6. Criteria for selecting the best model

\begin{tabular}{lrrl}
\hline Model & \multicolumn{1}{c}{ h-likelihood } & \multicolumn{1}{l}{ cAIC } & \multicolumn{1}{l}{ RMSE } \\
\hline M0 & 3473.10 & -6373.25 & 0.12226 \\
M1 & 3573.01 & -6519.81 & 0.12040 \\
M2 & 4231.94 & -5574.84 & 0.12804 \\
M3 & 3612.10 & -6526.14 & 0.12042 \\
M4 & 4485.46 & -5973.32 & 0.12310 \\
M5 & 3622.25 & -6503.19 & 0.12019 \\
M6 & 4499.07 & -5962.75 & 0.12303 \\
M7 & 3378.87 & -5754.17 & 0.13044 \\
\hline
\end{tabular}

Table 6 provides information that the RMSE value of all models is "relatively equal" so that the model selection based on the cAIC value. From the seven models compared, from the M0 model to the M6 model, the lowest cAIC value is given by the M2 model. Therefore the M2 model can be considered the best temporary model; Model M2 has a fixed component that only contains variables at the student level namely ESCS, INSTSCIE and EPIST without 
involving school-level variables and random elements of ESCS, INSTSCIE and EPIST which nested in schools. In the sense that students' mathematical literacy abilities are only determined by the characteristics of the students themselves without being determined by the features of the school. However, based on the results of testing the likelihood ratio between M2 models with the M3 model, the LRT statistic value is 358.73 with pvalue $<2.2 \times$ $10^{-16}$ which means that the M3 model is better than the M2 model.

Furthermore, the M3 Model is the best model candidate for mathematical literacy skills with a cAIC value of $-6526,136$. The M3 model involves variables at the student level and variables at the school level (without variable interaction) on the fixed component accompanied by random parts at the student level. The best model search is still carried out by conducting a likelihood ratio test on the M3 model with M5 and obtaining an LRT statistic of 211.64 with pvalue $<2.2 \times 10^{-16}$. This result cancels M3 as the best model. Thus the M6 model is the best temporary model.

Table 7. Estimate fixed component coefficients of the mean model M6

\begin{tabular}{lrrrrr}
\hline & \multicolumn{1}{l}{ Estimate } & \multicolumn{1}{l}{ Std. Error } & \multicolumn{1}{l}{$\mathrm{t}$-value } & $\operatorname{Pr}(>|\mathrm{t}|)$ & \\
\hline (Intercept) & $5.99 \mathrm{E}+00$ & $1.62 \mathrm{E}-02$ & 370.095 & $<2.00 \mathrm{E}-16$ & $* * *$ \\
ESCS & $4.16 \mathrm{E}-02$ & $1.25 \mathrm{E}-02$ & 3.316 & 0.000921 & $* * *$ \\
EPIST & $2.75 \mathrm{E}-02$ & $1.50 \mathrm{E}-02$ & 1.838 & 0.066067 & $\cdot$ \\
INSTSCIE & $5.78 \mathrm{E}-03$ & $1.50 \mathrm{E}-02$ & 0.385 & 0.700168 & \\
LEAD & $9.97 \mathrm{E}-03$ & $4.45 \mathrm{E}-03$ & 2.242 & 0.025009 & $*$ \\
EDUSHORT & $-2.45 \mathrm{E}-02$ & $3.75 \mathrm{E}-03$ & -6.553 & $6.24 \mathrm{E}-11$ & $* * *$ \\
PROSTCE & $6.73 \mathrm{E}-02$ & $1.60 \mathrm{E}-02$ & 4.215 & $2.55 \mathrm{E}-05$ & $* * *$ \\
TOTST & $1.32 \mathrm{E}-02$ & $1.19 \mathrm{E}-03$ & 11.045 & $<2.00 \mathrm{E}-16$ & $* * *$ \\
STRATIO & $-2.46 \mathrm{E}-05$ & $4.26 \mathrm{E}-04$ & -0.058 & 0.953996 & \\
SCHLTYPE 2 & $-6.54 \mathrm{E}-02$ & $1.19 \mathrm{E}-02$ & -5.483 & $4.41 \mathrm{E}-08$ & $* * *$ \\
ESCS_SCH & $-1.22 \mathrm{E}-04$ & $4.84 \mathrm{E}-05$ & -2.515 & 0.011923 & $*$ \\
ESCS:LEAD & $-2.69 \mathrm{E}-05$ & $3.27 \mathrm{E}-03$ & -0.008 & 0.993447 & \\
ESCS:EDUSHORT & $-5.61 \mathrm{E}-03$ & $2.64 \mathrm{E}-03$ & -2.121 & 0.03394 & $*$ \\
ESCS:PROSTCE & $2.52 \mathrm{E}-02$ & $1.04 \mathrm{E}-02$ & 2.413 & 0.015866 & $*$ \\
ESCS:TOTST & $-8.39 \mathrm{E}-04$ & $1.05 \mathrm{E}-03$ & -0.799 & 0.424384 & \\
ESCS:STRATIO & $-1.34 \mathrm{E}-04$ & $3.96 \mathrm{E}-04$ & -0.338 & 0.735115 & \\
ESCS:(SCHLTYPE)2 & $-1.76 \mathrm{E}-02$ & $9.92 \mathrm{E}-03$ & -1.768 & 0.077048 &. \\
ESCS:ESCS_SCH & $2.09 \mathrm{E}-05$ & $3.32 \mathrm{E}-05$ & 0.629 & 0.5293 & \\
EPIST:LEAD & $-9.78 \mathrm{E}-04$ & $4.01 \mathrm{E}-03$ & -0.244 & 0.807366 & \\
EPIST:EDUSHORT & $-4.14 \mathrm{E}-03$ & $3.29 \mathrm{E}-03$ & -1.258 & 0.208615 & \\
EPIST:PROSTCE & $3.87 \mathrm{E}-03$ & $1.26 \mathrm{E}-02$ & 0.307 & 0.759046 & \\
EPIST:TOTST & $1.86 \mathrm{E}-04$ & $1.24 \mathrm{E}-03$ & 0.15 & 0.8809 & \\
EPIST:STRATIO & $1.01 \mathrm{E}-04$ & $4.46 \mathrm{E}-04$ & 0.226 & 0.821035 &
\end{tabular}




\begin{tabular}{lrrrr} 
EPIST:(SCHLTYPE)2 & $-7.08 \mathrm{E}-03$ & $1.19 \mathrm{E}-02$ & -0.594 & 0.552548 \\
EPIST:ESCS_SCH & $1.48 \mathrm{E}-05$ & $3.18 \mathrm{E}-05$ & 0.465 & 0.641769 \\
INSTSCIE:LEAD & $-2.92 \mathrm{E}-03$ & $3.75 \mathrm{E}-03$ & -0.779 & 0.436222 \\
INSTSCIE:EDUSHORT & $-1.05 \mathrm{E}-03$ & $3.13 \mathrm{E}-03$ & -0.336 & 0.736946 \\
INSTSCIE:PROSTCE & $3.10 \mathrm{E}-03$ & $1.22 \mathrm{E}-02$ & 0.254 & 0.799798 \\
INSTSCIE:TOTST & $-7.11 \mathrm{E}-04$ & $1.17 \mathrm{E}-03$ & -0.606 & 0.544371 \\
INSTSCIE:STRATIO & $-3.10 \mathrm{E}-05$ & $4.49 \mathrm{E}-04$ & -0.069 & 0.945034 \\
INSTSCIE:(SCHLTYPE)2 & $3.18 \mathrm{E}-03$ & $1.17 \mathrm{E}-02$ & 0.272 & 0.785489 \\
INSTSCIE:ESCS_SCH & $-9.15 \mathrm{E}-06$ & $2.94 \mathrm{E}-05$ & -0.311 & 0.755899 \\
\hline
\end{tabular}

Based on the results of testing of the fixed component parameter coefficients of the M6 model in bel 7 are three variables do not significantly influence students' mathematical literacy skills at the 0.05 level, namely the EPIST and INSTSCIE variables at the student level and STRATIO at the school level. The results of testing the variable coefficient of interaction at the student level with variables at the school level are almost entirely insignificant except the coefficient of interaction between ESCS and two school-level variables, namely EDUSHORT and PROSTCE. With the results of testing this coefficient, it is possible to make improvements to the model by eliminating variables (at the student level and school level) that are not significant from the model (in the fixed component and the random component). The three variables eliminated from the model are EPIST, INSTSCIE and STRATIO. The model formed are called the M7 and written as:

$$
\begin{aligned}
L M=\gamma_{0}+\gamma_{1} E S C S & +\gamma_{2} L E A D+\gamma_{3} E D U S H O R T+\gamma_{4} \text { PROSTCE }+\gamma_{5} \text { TOTST } \\
& +\gamma_{6} \text { SCHTYPE }+\gamma_{7} \text { ESCS_SCH }+\gamma_{8}(E S C S \times L E A D) \\
& +\gamma_{9}(E S C S \times E D U S H O R T)+\gamma_{10}(E S C S \times P R O S T C E) \\
& +\gamma_{11}(E S C S \times \text { TOTS })+\gamma_{12}(E S C S \times S C H T Y P E) \\
& +\gamma_{13}\left(E S C S \times E S C S \_S C H\right)+u_{1} E S C S+e
\end{aligned}
$$

Estimate of fixed component coefficients in the M7 model is given in Table 8 while estimate of random component coefficients in Tabel 9.

Table 8. Estimate of fixed component coefficient of mean model M7

\begin{tabular}{lrrrrl}
\hline & \multicolumn{1}{c}{ Estimate } & Std. Error & $\mathrm{t}$-value & \multicolumn{1}{l}{$\operatorname{Pr}(>|\mathrm{t}|)$} & \\
\hline (Intercept) & $6.00 \mathrm{E}+00$ & $1.14 \mathrm{E}-02$ & 526.62 & $<2.00 \mathrm{E}-16$ & $* * *$ \\
ESCS & $4.77 \mathrm{E}-02$ & $1.17 \mathrm{E}-02$ & 4.086 & $4.47 \mathrm{E}-05$ & $* * *$ \\
LEAD & $6.28 \mathrm{E}-03$ & $3.65 \mathrm{E}-03$ & 1.724 & 0.08484 &. \\
EDUSHORT & $-2.90 \mathrm{E}-02$ & $3.07 \mathrm{E}-03$ & -9.438 & $<2.00 \mathrm{E}-16$ & $* * *$ \\
PROSTCE & $7.53 \mathrm{E}-02$ & $1.36 \mathrm{E}-02$ & 5.528 & $3.42 \mathrm{E}-08$ & $* * *$ \\
TOTST & $1.19 \mathrm{E}-02$ & $8.85 \mathrm{E}-04$ & 13.411 & $<2.00 \mathrm{E}-16$ & $* * *$ \\
as.factor(SCHLTYPE)2 & $-6.11 \mathrm{E}-02$ & $9.44 \mathrm{E}-03$ & -6.471 & $1.07 \mathrm{E}-10$ & $* * *$ \\
ESCS_SCH & $-1.44 \mathrm{E}-04$ & $4.47 \mathrm{E}-05$ & -3.213 & 0.00132 & $* *$ \\
ESCS:LEAD & $-7.10 \mathrm{E}-04$ & $3.51 \mathrm{E}-03$ & -0.202 & 0.83988 &
\end{tabular}




\begin{tabular}{lrrrrrl} 
ESCS:EDUSHORT & $-7.30 \mathrm{E}-03$ & $2.88 \mathrm{E}-03$ & -2.536 & 0.01126 & $*$ \\
ESCS:PROSTCE & $2.67 \mathrm{E}-02$ & $1.12 \mathrm{E}-02$ & 2.381 & 0.01731 & $*$ & \\
ESCS:TOTST & $-7.20 \mathrm{E}-04$ & $1.12 \mathrm{E}-03$ & -0.643 & 0.51999 & \\
ESCS:(SCHLTYPE)2 & $-1.98 \mathrm{E}-02$ & $1.05 \mathrm{E}-02$ & -1.895 & 0.05819 &. \\
ESCS:ESCS_SCH & $1.37 \mathrm{E}-05$ & $3.63 \mathrm{E}-05$ & 0.378 & 0.70529 & \\
\hline
\end{tabular}

*) significant at $\alpha=0.05, * *)$ significant at $\alpha=0.005$, ***) significant at $\alpha=0.0005$

Referring to Table 8, in the fixed component of the M7 model, most of the variables had a significant effect on the 0.05 significance level of achievement of mathematical literacy. These variables are ESCS, EDUSHORT, PROSTCE, TOTST, ESCS_SCH and SCHTYPE and interactions between ESCS and two school-level variables, namely EDUSHORT and PROSTCE. The LEAD variable does not give this effect, nor does the interaction of ESCS with other variables at the school level. The magnitude of the impact of random ESCS has a variety of values between one school and another. It exists in Table 9.

Table 9. Estimate random component coefficients of the M7 model

\begin{tabular}{lrrlrc}
\hline ESCS:School & Estimate & $\begin{array}{l}\text { Std. } \\
\text { Error }\end{array}$ & ESCS:School & Estimate & $\begin{array}{l}\text { Std. } \\
\text { Error }\end{array}$ \\
\hline ESCS:(CNTSCHID)1 & -0.0836 & 0.0188 & ESCS:(CNTSCHID)26 & 0.0032 & 0.0157 \\
ESCS:(CNTSCHID)2 & -0.0346 & 0.0151 & ESCS:(CNTSCHID)31 & 0.0665 & 0.0177 \\
ESCS:(CNTSCHID)3 & 0.0167 & 0.0109 & ESCS:(CNTSCHID)32 & -0.0622 & 0.0160 \\
ESCS:(CNTSCHID)4 & -0.0162 & 0.0170 & ESCS:(CNTSCHID)34 & 0.0045 & 0.0132 \\
ESCS:(CNTSCHID)5 & -0.0186 & 0.0134 & ESCS:(CNTSCHID)35 & -0.0262 & 0.0103 \\
ESCS:(CNTSCHID)7 & -0.0001 & 0.0193 & ESCS:(CNTSCHID)36 & 0.0288 & 0.0122 \\
ESCS:(CNTSCHID)9 & 0.0190 & 0.0124 & ESCS:(CNTSCHID)38 & -0.0032 & 0.0137 \\
ESCS:(CNTSCHID)10 & 0.0392 & 0.0107 & ESCS:(CNTSCHID)39 & -0.0046 & 0.0124 \\
ESCS:(CNTSCHID)11 & 0.0268 & 0.0105 & ESCS:(CNTSCHID)40 & 0.0117 & 0.0264 \\
ESCS:(CNTSCHID)13 & -0.0341 & 0.0149 & ESCS:(CNTSCHID)41 & 0.0196 & 0.0131 \\
ESCS:(CNTSCHID)14 & 0.0300 & 0.0174 & ESCS:(CNTSCHID)42 & 0.0004 & 0.0123 \\
ESCS:(CNTSCHID)15 & -0.0052 & 0.0106 & ESCS:(CNTSCHID)43 & -0.0092 & 0.0119 \\
ESCS:(CNTSCHID)16 & -0.0659 & 0.0107 & ESCS:(CNTSCHID)44 & 0.0315 & 0.0147 \\
ESCS:(CNTSCHID)17 & -0.0060 & 0.0291 & ESCS:(CNTSCHID)45 & 0.0074 & 0.0126 \\
ESCS:(CNTSCHID)18 & 0.0158 & 0.0247 & ESCS:(CNTSCHID)47 & 0.0022 & 0.0152 \\
ESCS:(CNTSCHID)20 & 0.0054 & 0.0113 & ESCS:(CNTSCHID)49 & 0.0220 & 0.0155 \\
ESCS:(CNTSCHID)21 & 0.0190 & 0.0100 & ESCS:(CNTSCHID)50 & -0.0293 & 0.0138 \\
ESCS:(CNTSCHID)22 & 0.0248 & 0.0114 & ESCS:(CNTSCHID)51 & 0.0127 & 0.0114 \\
ESCS:(CNTSCHID)23 & -0.0229 & 0.0217 & ESCS:(CNTSCHID)52 & -0.0063 & 0.0142 \\
ESCS:(CNTSCHID)24 & 0.0346 & 0.0114 & ESCS:(CNTSCHID)53 & -0.0274 & 0.0161 \\
ESCS:(CNTSCHID)25 & 0.0412 & 0.0133 & ESCS:(CNTSCHID)54 & -0.0304 & 0.0215 \\
ESCS:(CNTSCHID)55 & -0.0441 & 0.0165 & ESCS:(CNTSCHID)119 & -0.0289 & 0.0288
\end{tabular}




\begin{tabular}{|c|c|c|c|c|c|}
\hline 56 & 0089 & 12 & ESCS: & & \\
\hline ESCS:(CNTSCHID)57 & .0217 & & ESCS:(CNTSCHID) 121 & & \\
\hline JTSCHID)58 & & 0187 & ESCS:(CNTSCHID) 122 & -0.0171 & \\
\hline CS:(CNTSCHID) 59 & 0366 & 0086 & ESCS:(CNTSCHID) 123 & 66 & 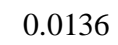 \\
\hline 50 & 51 & 113 & & & 332 \\
\hline VTSCF & & & 26 & & 62 \\
\hline HID) 62 & 0064 & 355 & NTSCHID) 127 & -0.0087 & 0299 \\
\hline NTSCHID)63 & 0000 & 0216 & ESCS:(CNTSCHID) 128 & $-0 .($ & \\
\hline TSCHID)66 & -0.0060 & 0150 & ESCS:(CNTSCHID) 129 & -0.0201 & 0278 \\
\hline D) 68 & -0.0 & 26 & JTSCHID) 130 & & 160 \\
\hline HID)70 & 1108 & 0154 & NTSCHID) 131 & -0.0191 & 0263 \\
\hline CHID)71 & -0.0 & 252 & ESCS:(CNTSCHID) 132 & 86 & 198 \\
\hline TSCHID)72 & -0.0 & 0163 & ESCS:(CNTSCHID) 133 & -0.0085 & 129 \\
\hline D) 73 & -0.0 & 269 & ESC & 0 & 11( \\
\hline ID)74 & 05 & 114 & NTSCHID) 135 & (2) & 143 \\
\hline ID)75 & -0.0209 & 0140 & NTSCHID)136 & -0.0262 & .011 \\
\hline 76 & & & NTSCH & 0.03 & 120 \\
\hline HID) 78 & 0.0327 & 0232 & NTSCHID)139 & 0190 & 117 \\
\hline 80 & 119 & 116 & ESC & 0.05 & 017 \\
\hline D) 81 & -0.0195 & 0163 & $\mathrm{ESC}$ & -0.0 & 130 \\
\hline ID) 82 & 334 & 01 & SCHID)142 & 32 & 29 \\
\hline 4 & 0 & 16 & 43 & -0. & 0177 \\
\hline 5 & & & & & 16 \\
\hline 6 & & 26 & NTSCHH & & 124 \\
\hline & & & ES & & 20 \\
\hline CHID)91 & 5100 & 277 & ESCS:(CNTSCHID) 147 & -0.0240 & 18 \\
\hline D)92 & -0.0016 & 0327 & ESCS:(CNTSCHID) 151 & 0173 & 028 \\
\hline & & & ESC & & \\
\hline ESCS:(CNTSCHID)96 & -0.0217 & 15 & ESCS:(CNTSCHID) 153 & 79 & 0141 \\
\hline & -0.0 & 147 & SCHID) 154 & -0 & 016 \\
\hline [SCHID)98 & -0.0119 & 195 & ESCS:(CNTSCHID) 155 & -0.0583 & 0.014 \\
\hline NTSCHID)99 & -0.0658 & .0215 & ESCS:(CNTSCHID) 157 & 38 & 0.0156 \\
\hline & & 115 & ESCS:(CNTSCHID) 160 & -0.0303 & 0.022 \\
\hline NTSCHID) 102 & & 00 & ESCS:(CNTSCHID) & & 123 \\
\hline ) 103 & -0.1 & 33 & HID) 163 & 15 & .014 \\
\hline HID) 104 & -0.0280 & & ESCS:(CNTSCHID) 165 & -0.0104 & 0.012 \\
\hline SCS:(CNTSCHID) 105 & -0.0465 & 153 & ESCS:(CNTSCHID) 168 & -0.0402 & 024 \\
\hline ESCS:(CNTSCHID) 107 & -0.0942 & 0141 & ESCS:(CNTSCHID) 169 & 0.0029 & \\
\hline
\end{tabular}




\begin{tabular}{|c|c|c|c|c|c|}
\hline ESCS:(CNTSCHID) 108 & 0.0049 & 0.0170 & ESCS:(CNTSCHID) 171 & 0.0776 & 0.0213 \\
\hline ESCS:(CNTSCHID) 109 & 0.0046 & 0.0173 & ESCS:(CNTSCHID) 172 & -0.0544 & 0.0351 \\
\hline ESCS:(CNTSCHID) 110 & -0.0170 & 0.0144 & ESCS:(CNTSCHID) 173 & 0.0243 & 0.0142 \\
\hline ESCS:(CNTSCHID) 111 & 0.0104 & 0.0190 & ESCS:(CNTSCHID) 174 & -0.0881 & 0.0132 \\
\hline ESCS:(CNTSCHID) 112 & -0.0186 & 0.0123 & ESCS:(CNTSCHID) 175 & -0.0157 & 0.0223 \\
\hline ESCS:(CNTSCHID) 114 & 0.0407 & 0.0156 & ESCS:(CNTSCHID) 176 & -0.0268 & 0.0120 \\
\hline ESCS:(CNTSCHID) 116 & -0.0878 & 0.0136 & ESCS:(CNTSCHID) 179 & 0.0299 & 0.0155 \\
\hline ESCS:(CNTSCHID) 117 & -0.0120 & 0.0103 & ESCS:(CNTSCHID) 180 & 0.0367 & 0.0104 \\
\hline ESCS:(CNTSCHID) 118 & -0.0399 & 0.0103 & ESCS:(CNTSCHID) 181 & -0.0239 & 0.0121 \\
\hline ESCS:(CNTSCHID) 182 & 0.0523 & 0.0164 & ESCS:(CNTSCHID)207 & 0.0133 & 0.0156 \\
\hline ESCS:(CNTSCHID) 183 & 0.0513 & 0.0129 & ESCS:(CNTSCHID)209 & 0.0163 & 0.0141 \\
\hline ESCS:(CNTSCHID) 184 & -0.0432 & 0.0153 & ESCS:(CNTSCHID)211 & 0.0385 & 0.0250 \\
\hline ESCS:(CNTSCHID) 185 & 0.0122 & 0.0122 & ESCS:(CNTSCHID)212 & 0.0072 & 0.0105 \\
\hline ESCS:(CNTSCHID) 186 & -0.0076 & 0.0120 & ESCS:(CNTSCHID)213 & 0.0568 & 0.0137 \\
\hline ESCS:(CNTSCHID) 187 & 0.0402 & 0.0097 & ESCS:(CNTSCHID)214 & 0.0012 & 0.0126 \\
\hline ESCS:(CNTSCHID) 189 & 0.0081 & 0.0144 & ESCS:(CNTSCHID)215 & 0.0446 & 0.0128 \\
\hline ESCS:(CNTSCHID) 190 & 0.0090 & 0.0157 & ESCS:(CNTSCHID)218 & 0.0282 & 0.0121 \\
\hline ESCS:(CNTSCHID)191 & -0.0204 & 0.0122 & ESCS:(CNTSCHID) 219 & -0.0180 & 0.0118 \\
\hline ESCS:(CNTSCHID) 193 & 0.0025 & 0.0106 & ESCS:(CNTSCHID)221 & 0.0397 & 0.0129 \\
\hline NTSCHID)194 & 0.0025 & 0.0135 & ESCS:(CNTSCHID) 222 & 0.0394 & 0.0109 \\
\hline ESCS:(CNTSCHID) 195 & 0.0273 & 0.0131 & ESCS:(CNTSCHID) 223 & 0.0006 & 0.0418 \\
\hline ESCS:(CNTSCHID) 196 & -0.0625 & 0.0131 & ESCS:(CNTSCHID)224 & 0.0159 & 0.0154 \\
\hline ESCS:(CNTSCHID) 197 & 0.0014 & 0.0103 & ESCS:(CNTSCHID)226 & -0.0586 & 0.0285 \\
\hline ESCS:(CNTSCHID) 198 & 0.0015 & 0.0106 & ESCS:(CNTSCHID)227 & -0.0320 & 0.0113 \\
\hline ESCS:(CNTSCHID) 199 & 0.0092 & 0.0126 & ESCS:(CNTSCHID)228 & 0.0186 & 0.0153 \\
\hline ESCS:(CNTSCHID)200 & 0.0178 & 0.0098 & ESCS:(CNTSCHID) 230 & 0.0551 & 0.0221 \\
\hline ESCS:(CNTSCHID)201 & 0.0549 & 0.0151 & ESCS:(CNTSCHID)232 & 0.0211 & 0.0120 \\
\hline ESCS:(CNTSCHID) 202 & -0.0257 & 0.0253 & ESCS:(CNTSCHID) 233 & -0.0151 & 0.0261 \\
\hline ESCS:(CNTSCHID)203 & -0.0278 & 0.0132 & ESCS:(CNTSCHID) 234 & 0.0142 & 0.0151 \\
\hline ESCS:(CNTSCHID)204 & 0.0081 & 0.0111 & ESCS:(CNTSCHID)235 & 0.0340 & 0.0104 \\
\hline ESCS:(CNTSCHID)205 & 0.0824 & 0.0142 & ESCS:(CNTSCHID) 236 & -0.0150 & 0.0151 \\
\hline
\end{tabular}

Variables of individual student socio-economic background (ESCS) (average/intercept) have a positive influence on students' mathematical literacy achievements, the higher the social status of students, the higher the achievement of mathematical literacy. It achievement indicated by a value of 0.0477 . But the influence of random background students makes the magnitude of this influence vary even there are several schools whose impact is negative. The interaction between the socio-economic status of students and the lack of material in school education (EDUSHORT) has a significant adverse effect on the achievement of mathematical 
literacy as indicated by the coefficient value of -0.0073 . Whereas the interaction between students' socio-economic status with the proportion of certified teachers (PROSTCE) contributes significantly to the achievement of mathematical literacy with a coefficient of 0.0267. In contrast to the individual socio-economic background of students, the average socio-economic status of students in the school (ESCS_SCH) negatively affects the achievement of mathematical literacy with a coefficient of $-1.44 \mathrm{E}-04$, increasing the socioeconomic average of students in a school resulting in a decrease in performance of mathematical literacy.

The lack of material in education in a school has a negative influence on the achievement of mathematical literacy, as indicated by the value of -0.029 . The pursuit of meeting school material needs must be carried out maximally by policymakers both in school leaders and the government to improve the quality of education.

The proportion of certified teachers and the number of science teachers (TOTST) positively influences the achievement of mathematical literacy. Therefore school leaders need to facilitate and encourage teachers who have not been certified to submit it to the government immediately. The school also needs to meet the ideal needs of the needs of science teachers.

The negative value on the coefficient of (SCHTYPE) 2 is -0.0611 indicates that public schools have a smaller effect than private schools. It can be an evaluation material for state schools which, in terms of financing, the provision of facilities and guidance and supervision are facilitated by the State to improve the quality of the education held. Even this improvement in the quality of education is a massive responsibility for the government as a manager of people's affairs.

The M7 model for the achievement of mathematical literacy with HGLM is said to be quite useful because it satisfies the assumptions of randomness and residual freedom as well as the homogeneity of residual variance. It indicates a residual pattern from a random model.
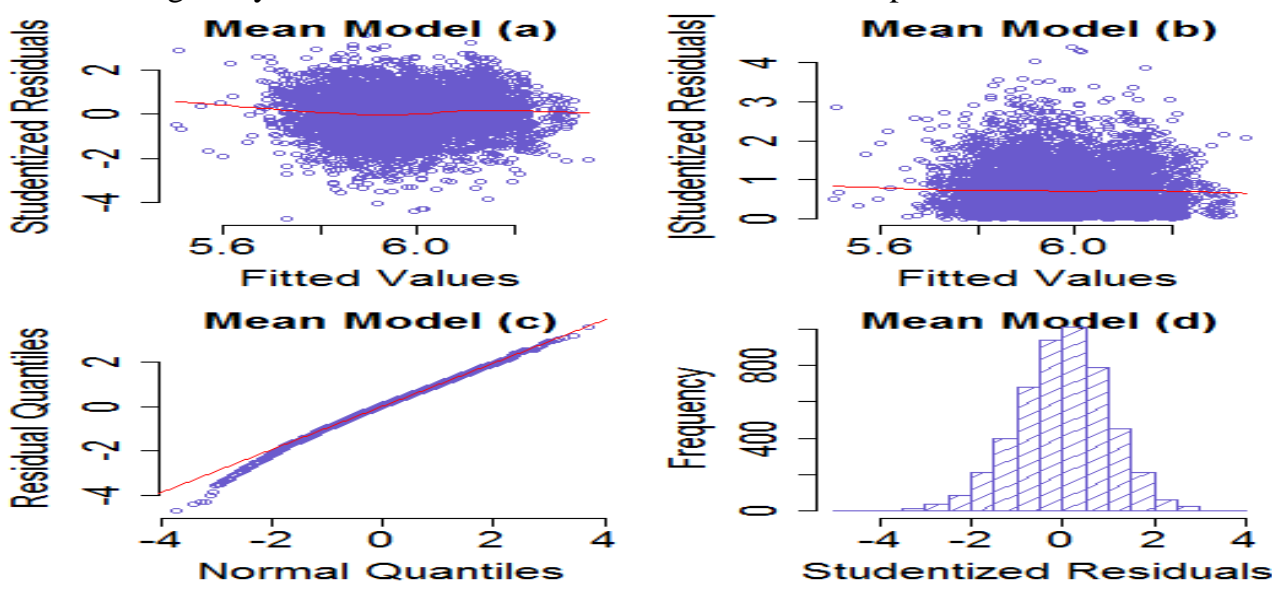

Fig. 3. Studendized Residual Vs Fitted Value Model M7

In this study only used data at one period. Therefore, further studies will be more comprehensive using longitudinal data. 


\section{Conclusion}

Multilevel generalized linear model is one form of HGLM. This model class can analize data with a hierarchical structure. On mathematical literacy achievement in 2015 PISA data for Indonesia has lognormal distribution. there are some variables given significantly positive influences to mathematical literacy achievement namely the proportion of certified teachers, number of science teachers, students' socio-economic background and interaction's with ratio of certified teachers. Whereas the variables that significantly negative are the lack of educational material, the average socioeconomic background of the students and interaction's with lack of educational learning material and the number of certified teachers. Private schools significantly provide a more significant influence on student mathematics literacy achievement compared to public schools.

\section{References}

[1] De Leeuw, J. dan Kreft, I.: Random coefficient models for multilevel analysis. Departement of Statistics Paper. Departement of Statistics, UCLA, Los Angeles. http://preprints.stat.ucla.edu/496/dLK_jes.pdf (19 Mei 2019). (2006).

[2] Delignete, ML. Muller.: Fitdistrplus: an R packages for fitting distribution. Accepted in Journal of Statistical Software. (2018)

[3] Goldstein H.: Multilevel statistical model $4^{\text {th }}$ Edition. England: John Wiley \& Sons Ltd, (2011).

[4] Gürsakal, S., Murat, D., Gürsakal, N.: Assessment of PISA 2012 results with quantile regression analysis within the context of inequality in educational opportunity. Alphanumeric Journal . 4(2): 41-54, (2016).

[5] Hox, J.J.: Applied multilevel analysis, 1st edition, TT-Publikaties, Amsterdam. 119, (1995).

[6] Hox, J.J., Roberts, J.K: Hand book advanced multilevel analysis. Newyork:Routledge, (2011).

[7] Hox, J.J.: Multilevel analysis techniques and applications : Quantitative Methodology Series 3nd Edition. New York: Routledge, (2018).

[8] Lee, Y., Nelder, J.A.: Hierarchical generalized linear models. Journal of the Royal Statistical Society. Series B (Methodological). 58(4): 619-678, (1996).

[9] Lee, Y., Nelder, J.A., Pawitan, Y.: Generalized linear models with random Effect. unified analysis via h-likelihood. Newyork:CRCPress, (2017).

[10] McCullagh, P., Nelder, JA.: Generalized linear models. $2^{\text {th }}$ Edition. London: Chapman and Hall, (1989).

[11] Özdemir, C.: Equity in the Turkish education system: A multilevel analysis of sosial background influences on the mathematics performance of 15-year-old students. European Educational Research Journal. Vol 15(2): 193-217, (2016).

[12] Skrondal, A., Hesketh, S.R.: Prediction in multilevel generalized linear models. Royal Statistical Society. 172(3 ): 659-687, (2009).

[13] Tantular, B.: Penerapan model regresi linear multilevel pada data pendidikan dan data nilai ujian [application of linear regression multilevel models to education data and exam score data]. [Tesis]. Bogor (ID): Institut Pertanian Bogor, (2009).

[14] Ubaidillah, A. Kurnia, A. Sadik, K.: Generalized multilevel linear model dengan pendekatan bayesian untuk pemoelan data pengeluaran perkapita rumah tangga [Generalized multilevel linear model with bayesian approach to modeling expenditure data per captain household]. Jurnal Aplikasi Statistika dan Komputasi Statistika. 9 (1): 19-30, (2017).

[15] Widiastuti M. 2011. Kajian terhadap faktor-faktor yang mempengaruhi pencapaian siswa bidang matematika menggunakan pemodelan multilevel [Analysis of factors influence student's mathematic achievement using multilevel modelling]. [Tesis]. Bogor (ID): Institut Pertanian Bogor. 
[17] Wu H., Hao X., Shen, J. 2019. Principal leadership effects on student achievement: a multilevel analysis using Programme for International Student Assessment 2015 data. Educational Study. https://doi.org/10.1080/03055698.2019.1584853.

[18] Zulvia, P., Kurnia, A., \& Soleh, A. M.: Multilevel modeling and panel data analysis in educational research (Case study: National examination of senior high school data in West Java). In AIP Conference Proceedings (Vol. 1827, No. 1, p. 020004). AIP Publishing, (2017). 